\title{
Assessment of the relationship between life events with psychosocial competence of students in selected secondary schools in Northern and Central Uganda
}

\author{
Wilson Winstons Muhwezi ${ }^{1}$, Catherine Abbo ${ }^{1,3}$, Elialilia S Okello ${ }^{4}$, Grace Akello², Emilio B L Ovuga ${ }^{2}$
}

1. Makerere University College of Health Sciences, School of Medicine, Department of Psychiatry, P. O. Box 7072, Kampala, Uganda

2. Department of Psychiatry, Faculty of Medicine, Gulu University P. Box 126, Gulu.

3. Division of Child and Adolescent Psychiatry, Red Cross War Memorial Hospital, University of Cape

Town, 7700, Rondebosch, Cape Town

4. Mwanza Intervention Trials Unit, National Institute for Medical Research, Mwanza Centre TZ.

\section{Co-authors' emails:}

Catherine Abbo: cathya180@gmail.com; Elialilia S Okello: elly@chs.mak.ac.ug; Grace Akello: akellograce@hotmail.com; Emilio B L Ovuga: emilio.ovuga@gmail.com

\begin{abstract}
Introduction: As they grow, young people transit through adolescence; a particularly challenging phase. Many go through without difficulties but some experience maladaptive responses in form of conduct and adjustment problems, pubertal challenges and life stress. Published research from the developed societies demonstrates consistent associations between young people's exposure to life events, psychosocial competence (PSC) and mental health problems. However, comparable research from income-constrained societies remains scarce. The purpose of this study was to determine the prevalence of life events in secondary school students and describe the relationship between life events and PSC in the same population.

Methods: This was a cross-sectional study. Participants were 2,902 randomly selected in Central and Northern Uganda. They responded to self-administered questionnaires on socio-demographics, life events and PSC.

Results: Northern Ugandan students were more likely to be susceptible to stress-related illness associated with major life events $(\mathrm{p}=<0.01)$. Among students with a high susceptibility to stress related illness, those with low scores on self-efficacy $(\mathrm{p}=<0.001)$, accurate self-assessment $(\mathrm{p}=<0.001)$ and self-confidence $(\mathrm{p}=<0.001)$ were mostly from the North. Students from Northern Uganda had experienced more negative events. Students with higher scores on empathy, emotional awareness, accurate self- assessment and self-confidence tended to have low distress. Students that had a low susceptibility to stress related illness (AOR $=1.97$; 95\% CI: 1.57 - 2.48); high scores on self-efficacy (AOR 1.37; 95\% CI: 1.09 - 1.74), self-confidence (AOR 1.32; 95\% CI: 1.02- 1.72), and accurate self-assessment (AOR 2.19; 95\% CI: 1.70 - 2.80) were mostly from northern Uganda.

Conclusion: It is important to help students to cope with negative life events since an association exists between negative life events and PSC domains. PSC domains of empathy, emotional awareness, accurate self-assessment and self-confidence seem to be associated with lower distress levels, implying that these should be reinforced.
\end{abstract}

Keywords: Psychosocial competence, life events, adolescents, students, Uganda.

DOI: https://dx.doi.org/10.4314/ahs.v20i3.48

Cite as: Mubwezi WW, Abbo C, Okello ES, Akello G, Ovuga EBL. Assessment of the relationship between life events with psychosocial competence of students in selected secondary schools in Northern and Central Uganda. Afri Health Sci. 2020;20(3): 1426-1437. bttps://dx.doi.org/10.4314/abs.v20i3.48

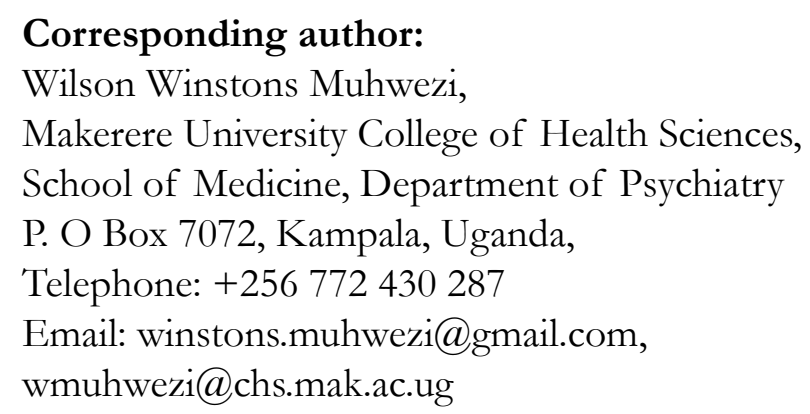

\section{Background}

Young people go through adolescence which is a particularly challenging phase of growth and development. Adolescence as a developmental phase is marked by discovery and experimentation. It is marked by rapid physical and psychological changes that transcend both biological and cognitive functioning. It is marked by expanding complex social roles and environments that expose young people to a widening array 
of stressors and life- shaping choices. In spite of all this, most adolescents transition through this period seamlessly ${ }^{1}$. However, some experience maladaptive challenges due to biological, psychological, and social changes. This may take the form of conduct problems, adjustment problems, pubertal transitional challenges and life stress ${ }^{1-3}$. In Northern Uganda, the consequences of displacement due to war on adolescents and children could have extended beyond killing and injury to include not only denial of material and emotional needs but complete fragmentation of their society. The mental functioning of adolescents in such a setting could have been affected and their ability to focus on their competencies could have been undermined. This is by no means different to those in Kampala city, especially the urban poor. The urban poor are inadequately served with social services; and experience stress associated with poverty and unemployment, crime, overcrowding in poor houses and inadequate sanitation ${ }^{4,5}$.

Like elsewhere, adolescence in Africa is marked by "transitioning" in the school system from primary to secondary, from secondary to high school or to college or work, and from living with parents to living independently ${ }^{1-3}$. Adolescence is an optimal time for learning new coping skills to reduce the adverse effects of stressful events. It is a significant period worthy of investigation, especially the relationship between Psychosocial Competence (PSC) ${ }^{6-8}$ and life events. There is paucity of research from Sub-Saharan Africa (SSA) on this topical area.

Life events have on the other hand been conceptualized as: 'dateable occurrences representing discrete changes in the subject's social or personal environment that is external and verifiable rather than internal or psychological' 9, ${ }^{10}$. Life events; whether undesirable or desirable disrupt or threaten to disrupt an individual's usual activities. They include major and minor stresses, losses, achievements, and status changes that occur in people's lives and they often require a person to undergo psychosocial adjustment to function well ${ }^{11-15}$. Examples of common life events include, but are not limited to; break-up of intimate romantic relationships, death of a family member or friend, economic hardships, poor physical health, accidental and intentional assaults on physical safety, changes in occupational environment and legal predicaments, parent's divorce, and expulsion from school all of which exist both in Northern and Central Uganda like in other human societies.
Life events are of such a nature that affects interpersonal relationships as well as work and school activities. Literature affirms that they are likely to be predictive of young people's emotional and behavioral functioning. Among in-school young people, these changes are known to adversely influence scholastic and vocational attainment, development of self-esteem, capacity for satisfying relationships and the sense of wellbeing ${ }^{16-19}$. Such changes are known to underpin the mental health of youths. The combined effect of these changes on PSC and overall mental health in income-constrained societies like in much of Uganda has not been described.

Psychosocial competence is a known moderator that affects and is affected by stressful life events ${ }^{6,7}$. It is known to facilitate effectiveness in coping and to inhibit maladaptive responses to stressful life events ${ }^{20}$. However, little is known about the interplay of life events and PSC in a sub-Saharan Africa adolescent population. The debate about "objective" vs "subjective" or "independent" vs "dependent" nature of life events and the determination of the objective negative impact of life events on well-being has raged over a long time but now seems to have been resolved ${ }^{13,15,21-24}$

Negative life events and negative affect among adolescents are known to be related to substance use while factors like parent's emotional and instrumental support, academic and adult competence and positive affect are related to a low level of substance use ${ }^{25}$. Negative life events appear to elevate negative affect and place the adolescent at an increased risk for substance use $^{25}$ and poor academic achievement ${ }^{26}$. In this study, we postulated that negative life events were positively associated with poor psychosocial competence. The aims pursued in this study were; (i) to determine the prevalence of life events in secondary school students in Central and Northern Uganda and (ii) to describe the relationship between life events and psychosocial competence in students from the two regions.

\section{Study Methods}

\section{The Study Setting and Context}

Uganda is a multicultural society and nearly every region has tribal groupings of people with a distinct culture. The social ecology of young people in these cultural enclaves is embedded in a historical context. The implication is that each young person is influenced by many 
factors as he or she navigates through life milestones and phases of life ${ }^{27}$. The geographic, demographic, socio-economic, political and cultural setting of Gulu and Kampala districts representing Northern and Central Uganda respectively has been described elsewhere ${ }^{28}$.

\section{The Study Design}

This was a cross-sectional survey of two purposively selected regions. In Kampala district, 8 secondary schools (4 Government owned and 4 privately owned schools) were randomly selected. From each category, 2 secondary schools located in urban and 2 in peri-urban area were selected. From Gulu district, 4 schools were selected (2 Governments owned and two privately owned schools). There were no private secondary schools in rural Gulu at that time of this study. Therefore, all the private schools were selected from the urban area. In selecting schools, a list of privately-owned and Government-owned schools in rural and urban locations was accessed from respective District Education Offices and Kampala Capital City Authority. The schools were then separated regionally and the desired sample randomly selected.

The principal authors worked closely with the research assistants to solicit written assent of study participants aged below 18 years and written consent of their parents or guardians as well as written consent of study participants aged above 18 after which self- administered questionnaires were given to and filled by all study participants. All members of the research team were first trained on how to use the study instruments and in conducting ethical research.

\section{Sample size determination}

The Quantitative sample was calculated using the Kish Leslie formula for survey studies ${ }^{29}$. It was assumed that the occurrence of psychosocial competence was 50\%, confidence level was taken to be $95 \%$ and desired precision was set at 0.05 . Using these parameters, a total of about 400 young people per school was estimated giving an anticipated sample of about 3,200 in 12 schools. Eight schools were selected from Kampala district. The total student population in the two districts was 100,397 since student enrollment in Kampala was 89,124 and 11,273 in Gulu by $2009^{30}$. The sampling fraction used to sample students to participate in the two regions was computed to be $(3,200 / 100,397=0.032)$. While the sampled proportion of students in Gulu was $(0.032 \mathrm{x}$ $11,273=360.7=361)$, it was $(0.032 \times 89,124=2,851.9$

\section{$=2,852)$ in Kampala}

In Gulu, there were 19 registered secondary schools, 9 of which were located in the municipality.

Out of the 9, 3 were private schools and 6 were Government-aided ${ }^{31}$. The other 10 were located in rural areas and they were Government-aided. Simple random sampling (lottery method) was used to select 4 schools in Gulu district. The populations in the 4 schools were: $(899+831+2,000+1,689)$ giving a total population of 5,419 students. The sampling fraction used to pick students from each school to participate in the district was computed to be $361 / 5,419=0.067$. This fraction was multiplied by the population of each school to get the sample in each school. Though the computed sample in Gulu was 363, this was increased to 400 to take care of likely refusals to consent and spoilt questionnaires. A total of 404 students from Gulu district filled questionnaires but 4 were grossly incomplete and discarded at analysis. In Kampala, the desired sample of students was 2,852, number of target schools was 8 and the total number of students in the 8 schools was 11,039 . The procedure of determining the required number of students in the sample from each school was computed to be $2,852 / 11,039=0.26$. The total population in each of the 8 schools was multiplied by the sampling fraction to select school samples. To calculate the number of respondents required for each class, the total class population was divided by the total school population. The computed fraction was then multiplied by the total number of students required for the school to get the desired student number per class.

\section{Study Participants}

In each class, every fifth student was enrolled till the desired sample size was reached. Senior one and senior five students had not reported to schools by the time of the study. With a response rate of $100 \%$ in Gulu and $87.7 \%$ in Kampala, a total sample of 2,902 students participated in the study. Sampling was done within the school compounds because the schools could not allow moving class lists out of the school vicinity.

\section{Study Instruments \\ Socio-demographic questionnaire}

All students completed a demographic data sheet, which had questions on gender, age, class in school, religious affiliation, parenthood status, orphanhood status (for orphans), experience with domestic violence, nature of housing, number of rooms in a house where they lived and history of mental illness. 


\section{The Emotional Competence Inventory (ECI)}

The ECI was used to assess psychosocial competence. The ECI is a 360-degree tool designed to assess the emotional and social competencies of individuals. The test is based on emotional competencies identified by Dr. Daniel Goleman in working with Emotional Intelligence ${ }^{32}$. The desired attributes were extracted and assessed. Decision making/problem solving was assessed on 5 point likert scale of; (1) almost always, (2) usually, (3) about half the time, (4) rarely and (5) never. Self-efficacy, accurate self-assessment and self-confidence were assessed on 5 point likert scale of; (1) strongly disagree, (2) disagree, (3) undecided, (4) agree and (5) strongly agree. Empathy, emotional awareness and coping with emotions were assessed on 6 point likert scale of; always, (2) very frequently, (3) occasionally, (4) rarely, (5) very rarely and (6) never. Coping with stress was assessed on 5 point likert scale of; (1) very much, (2) often, (3) sometimes, (4) rarely and (5) not at all. The internal consistency of the scale items used was within acceptable range of cronbach's alpha 0.60 .

\section{The Life Events Scale}

Major life events encountered by the young people in the study were assessed using the Life Events Stress Scale ${ }^{13}$. It is a 43 stressful life events item scale with a value of each stress unit ranging from 11 to 100 (11 giving the least stress and 100 the most stressful). This scale measures the amount of change, using Life Change Units, a person experienced and adjusted to the previous 12 months ${ }^{12,13}$. It was designed to predict the likelihood of disease and illness following exposure to stressful life events. Each life event is given a score that indicates the amount of readjustment a person has to make as a result of the event. Not all the events in the scale are necessarily negative events. This scale indicates that change in one's life requires an effort to adapt and then an effort to regain stability. Unlike other scales, this scale considers only the events that occurred, not individual perception of these events in life ${ }^{33}$.

This scale shows the kind of life pressure that people have faced. Depending on the coping skills or lack thereof, the scale has the ability to predict the likelihood that a person could succumb to stress related illness. After the person ticks off the relevant items to him or her, the scores are summed and the total interpreted as follows; 0-149 (Low susceptibility to stress related illness, 150-299 (Medium susceptibility) and 300 and over (High susceptibility). This scale was adapted to fit the young persons' situations in Uganda. During data analysis in this study, we combined low and medium to form one category of low susceptibility to stress-related illness.

\section{Ethical Considerations}

Ethical clearances were obtained from the Research and Ethics Committees of Makerere University Medical School (Uganda) and Uganda National Council for Science and Technology Committee on study of Human Subjects. Administrative clearance was obtained from Ministry of Education and Sports as well as relevant District Education Officers. The head teachers of the sampled secondary schools allowed the study in their schools. Assent and consent was sought from all study participants at the time of recruitment. All those who declined to participate in the study were treated with respect and without prejudice. What to expect as a participant was made clear to all respondents. Confidentiality of information supplied by research participants and the anonymity of respondents were given utmost respect. Generally, conduct during the study adhered to the Helsinki Declaration ${ }^{34}$.

\section{Data Management and Statistical Analyses}

We entered data in EpiData, Version 3 and exported it to the Statistical Package for Social Scientists (SPSS) version 11.0 for cleaning, editing and analysis. We compared young people from central and northern Uganda on selected socio-demographics, susceptibility to stress related illness and major life events using frequency distributions and a two-way contingency table analyses (Pearson's $\chi^{2}$ test). Binary logistic regression (backward stepwise) was used to evaluate the predictive ability of life events on domains of psychosocial competence. The association between categorical life events and selected socio-demographics with domains of psychosocial competence (PSC) was determined. Each domain of PSC was entered as: low $=1$, high $=0$. The Chisquare test was used to compare proportions. Statistical tests of significance were set at $\mathrm{p}<0.05$.

\section{Findings}

The response rate in the study was $90.3 \%$. Students who completed the questionnaires were 2,902 aged between 12 and 24 years. Their overall mean age was 16.5 (SD \pm 1.9 ) years. However, students from Northern Uganda were slightly older (16.8; SD \pm 1.7$)$ than their counterparts in the Central region (16.4, SD 土1.9) $(\mathrm{p}<0.0001, \mathrm{t}$-test). For males, the mean age of 
students was slightly higher for Northern Uganda (16.9, $\mathrm{SD} \pm 1.6)$ compared to Central Uganda (16.6, SD \pm 1.9$)$ $(p=0.02$, t-test). For females, the mean age was still slightly higher for Northern Uganda (16.6, SD \pm 1.7 ) compared to Central Uganda (16.2, SD \pm 1.8$)(p=0.03$, t-test). By gender, there were 1,459 male students and 1,443 female students. The rest of the socio-demographic profiling is reported elsewhere ${ }^{6}$.

\section{Major Life Events and Psychosocial Competence}

We used data from the life events scale to determine the prevalence of life events as a proxy of susceptibility to stress-related illness. A higher aggregate score indicated a higher susceptibility to stress-related illness. The proportion of students with low susceptibility to stress-related illness (ranging from 0-149) in Central Uganda was $23.1 \%$ (577) compared to $15.8 \%$ (63) from Northern Uganda. The proportion with medium susceptibility to stress-related illness (ranging from 150-299) in Central Uganda was $28.1 \%$ (577) compared to $18.8 \%$ (75) from Northern Uganda. A significantly higher proportion of students from Northern Uganda 65.5\% $(1,221)$ had a higher likelihood of being highly susceptible (ranging from 300 and above) to stress-related illness compared to $48.8 \%$ (262) from the Central region Crude Odds ratio (OR): 1.97 (95\% CI: $1.45-2.66) ; \mathrm{p}=<0.01$.

\section{Psychosocial Competence and High Susceptibility to Stress Related Illness in the Last 12 Months}

Analysis of the relationship between domains of PSC among students with a high susceptibility to stress relat- ed illness (1,221 for Central region and 262 for Northern region) revealed proportionately more students with a low score on self-efficacy from the Northern region (37\%) compared to those from the Central region (25.4 \%) Crude OR: 1.73 (95\% CI: $1.29-2.31$ ); $\mathrm{p}=<0.001$. Similarly, students with a low score on accurate self-assessment Crude OR: 2.65 (95\% CI: 1.97 - 3.56); p = $<0.001$ and self-confidence Crude OR: 1.84 (95\% CI: $1.35-2.49) ; \mathrm{p}=<0.001$ in Northern region had significantly higher proportions compared to those from the Central region. There were no significant differences on other domains of PSC.

\section{Domains of PSC and Level of Susceptibility to Stress Related Illness in the Last 12 Months by Re- gion}

Table 1 shows the relationship between domains of PSC and level of susceptibility to stress-related illness stratified by region. In the Central region, more students with a high score on empathy were less likely to be susceptible to stress-related illness Crude OR: (95\% CI: $0.72-0.98) ; p=0.03$. Similarly, those with high scores on emotional awareness and self-confidence were marginally protected from a high susceptibility to stress-related illness. In northern region, the proportion of students with a low susceptibility to stress related illness was significantly higher among those who scored highly on decision making/problem solving Crude OR: 1.68 (95\% CI: $1.01-2.80) ; \mathrm{p}=0.04$ and coping with emotions illness Crude OR: 1.69 (95\% CI: 1.10 - 2.61); $\mathrm{p}=0.02$. Other analyses in the stratum did not reveal any significant differences. 


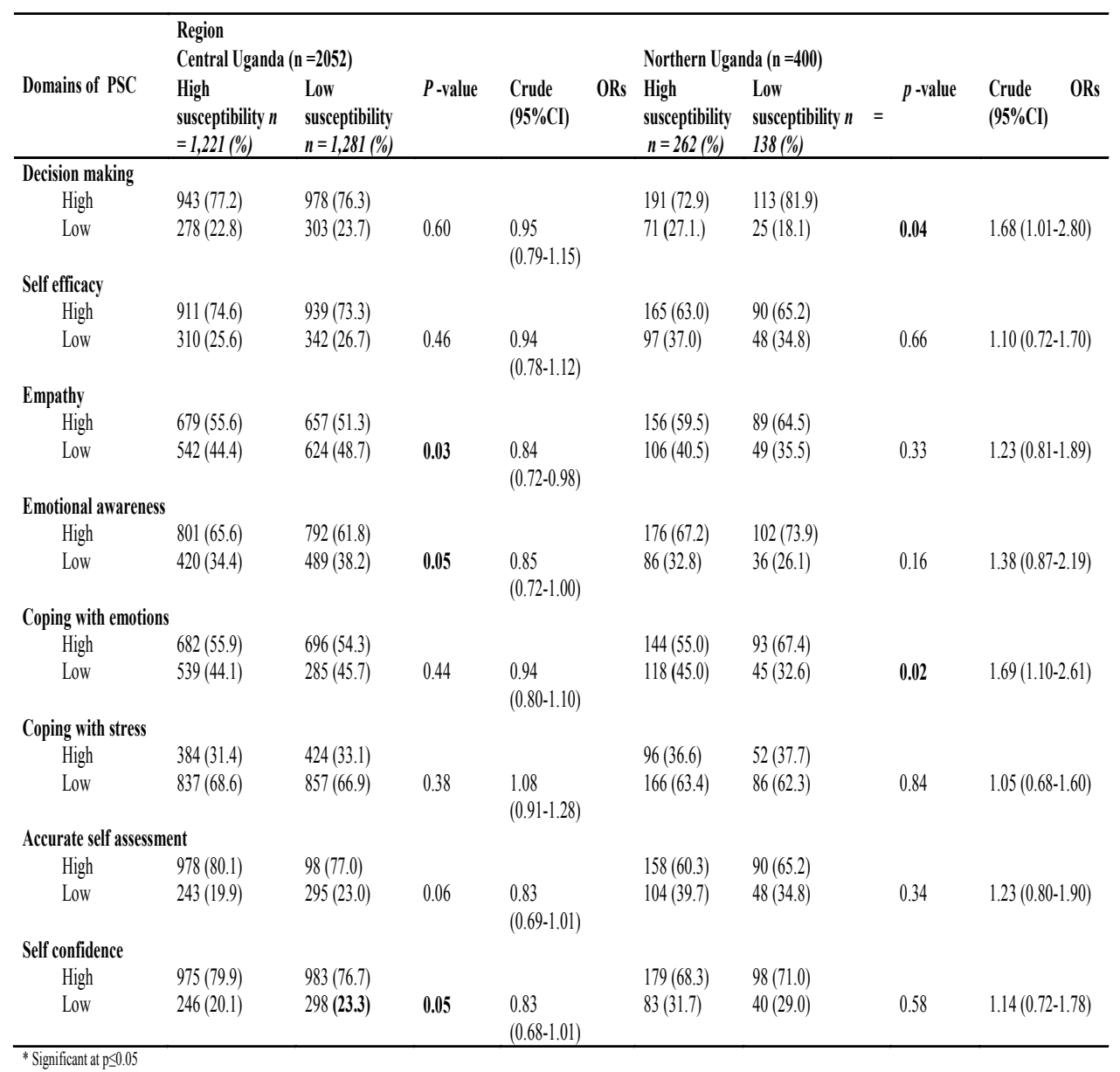

The Relationship between Distress Associated with Life Events and Psychosocial Competence by Region

In the Central region, a significantly bigger proportion of students with high self-efficacy Crude OR: 1.26 (95\% CI: $1.26-1.81) ; \mathrm{p}<0.001$ and high accurate self-assessment Crude OR: 1.49 (95\% CI: 1.23 - 1.82); p < $0.001 \mathrm{had}$ low levels of distress as indicated in Table 2. However, a bigger proportion of students with high scores on self-efficacy Crude OR: 0.79 (95\% CI: 0.67 $0.93) ; p=0.003$ and coping with emotions Crude OR: (95\% CI: $0.72-0.99) ; \mathrm{p}<0.04$ had slightly higher levels of distress. In the Northern region, a significantly bigger proportion of students high emotional awareness Crude OR: 1.26 (95\% CI: $1.03-2.54) ; \mathrm{p}<0.03$ and high accurate self-assessment Crude OR: 1.65 (95\% CI: $1.08-2.54) ; \mathrm{p}<0.02$ had low distress associated with negative life events. Other analyses in the stratum did not reveal any significant differences. 
Table 2: Domains of PSC by Level of Distress Associated with Negative Life Events Stratified by Region

\begin{tabular}{|c|c|c|c|c|c|c|c|c|}
\hline \multirow[b]{3}{*}{$\begin{array}{l}\text { Domains } \\
\text { of PSC }\end{array}$} & \multicolumn{8}{|c|}{ Region } \\
\hline & \multicolumn{4}{|c|}{ Central $(n=2,497)$} & \multicolumn{4}{|c|}{ Northern $(n=393)$} \\
\hline & $\begin{array}{c}\text { Low } \\
\text { distress } \\
n=1,381(\%)\end{array}$ & $\begin{array}{c}\text { High } \\
\text { distress } \\
n=1,116(\%)\end{array}$ & $p$-value & Crude ORs (95\%CI) & $\begin{array}{c}\text { Low } \\
\text { distress } \\
n=211 \\
(\%)\end{array}$ & $\begin{array}{c}\text { High } \\
\text { distress } \\
n=182(\%)\end{array}$ & $\begin{array}{c}p- \\
\text { value }\end{array}$ & Crude ORs $(95 \% \mathrm{CI})$ \\
\hline \multicolumn{9}{|c|}{ Decision making } \\
\hline High & $1,054(76.3)$ & $864(77.4)$ & & & $161(76.3)$ & $137(75.3)$ & & \\
\hline Low & $327(23.7)$ & $252(22.6)$ & 0.52 & $0.94(0.78-1.14)$ & $50(23.7)$ & $45(24.7)$ & 0.81 & $1.06(0.65-1.72)$ \\
\hline \multicolumn{9}{|l|}{ Self efficacy } \\
\hline High & $1,070(77.5)$ & $776(69.5)$ & & & $62(34.1)$ & $120(65.9)$ & & \\
\hline Low & $311(22.5)$ & $340(30.5)$ & $>0.001$ & $1.26(1.26-1.81)$ & $80(37.9)$ & $131(62.1)$ & 0.43 & $0.85(0.55-1.31)$ \\
\hline \multicolumn{9}{|l|}{ Empathy } \\
\hline High & $700(50.7)$ & $632(56.6)$ & & & $131(62.1)$ & $109(59.9)$ & & \\
\hline Low & $681(49.3)$ & $484(43.4)$ & 0.003 & $0.79(0.67-0.93)$ & $80(37.9)$ & $73(40.1)$ & 0.66 & $1.09(0.72-1.68)$ \\
\hline \multicolumn{9}{|c|}{ Emotional awareness } \\
\hline High & $857(62.1)$ & $732(65.6)$ & & & $156(73.9)$ & $116(63.7)$ & & \\
\hline Low & $524(37.9)$ & $384(34.4)$ & 0.07 & $0.86(0.73-1.02)$ & $55(26.1)$ & $66(36.3)$ & 0.03 & $1.16(1.03-2.54)$ \\
\hline \multicolumn{9}{|c|}{ Coping with emotions } \\
\hline High & $735(53.2)$ & $640(57.3)$ & & & $122(57.8)$ & $111(61.0)$ & & \\
\hline Low & $646(46.8)$ & $476(42.7)$ & 0.04 & $0.85(0.72-0.99)$ & $89(42.2)$ & $71(39.0)$ & 0.52 & $0.88(0.57-1.34)$ \\
\hline \multicolumn{9}{|c|}{ Coping with stress } \\
\hline High & $466(33.7)$ & $341(30.6)$ & & & $85(40.3)$ & $57(31.3)$ & & \\
\hline Low & $915(66.3)$ & $775(69.4)$ & 0.09 & $1.49(1.23-1.82)$ & $126(59.7)$ & $125(68.7)$ & 0.07 & $1.48(0.96-2.29)$ \\
\hline \multicolumn{9}{|c|}{ Accurate self assessment } \\
\hline High & $1,126(81.5)$ & $834(74.7)$ & & & $141(66.8)$ & $100(54.9)$ & & \\
\hline Low & $255(18.5)$ & $282(25.3)$ & $>0.001$ & $1.49(1.23-1.82)$ & $70(33.2)$ & $82(45.1)$ & 0.02 & $1.65(1.08-2.54)$ \\
\hline \multicolumn{9}{|c|}{ Self confidence } \\
\hline High & $1,106(80.1)$ & $847(75.9)$ & & & $153(72.5)$ & $118(64.8)$ & & \\
\hline Low & $275(19.9)$ & $269(24.1)$ & 0.01 & $1.23(1.05-1.55)$ & $58(27.5)$ & $64(35.2)$ & 0.10 & $1.43(0.91-2.25)$ \\
\hline
\end{tabular}

Students in the Central region that proportionately had higher scores on decision making, empathy, emotional awareness, coping with emotions, accurate self-assessment and self- confidence were more likely to have lower levels of distress as shown in Table 3. Conversely, students in the Northern region that had high scores on empathy, emotional awareness, accurate self-assessment and self-confidence were also more likely to have lower levels of distress associated with positive life events. Logistic Regression of Students' Placement by Region Multivariate analysis was done to assess the association between covariates and the region of belonging for students in the study. The covariates were gender, domicile, type of student (boarding or day scholar), PSC and domains of decision making/problem solving, self-efficacy, empathy, emotional awareness, coping with emotions, coping with stress, self-confidence and accurate self-assessment, susceptibility to stress related illness, negative daily life events and positive life events. Male gender, rural residence, being a day student and hailing from Northern region were entered in the model as 1 and the alternative option as a 2 . 
Table 3: Domains of PSC by Level of Distress Associated with Positive Life Events Stratified by Region

\begin{tabular}{|c|c|c|c|c|c|c|c|c|}
\hline \multirow[b]{3}{*}{$\begin{array}{l}\text { Domains } \\
\text { of PSC }\end{array}$} & \multicolumn{8}{|c|}{ Region } \\
\hline & \multicolumn{4}{|c|}{ Central $(n=2,473)$} & \multicolumn{4}{|c|}{ Northern ( $\mathrm{n}=394)$} \\
\hline & $\begin{array}{c}\text { Low } \\
\text { distress } \\
n=1,362(\%)\end{array}$ & $\begin{array}{c}\text { High } \\
\text { distress } \\
n=1,111 \\
(\%)\end{array}$ & $\begin{array}{c}p- \\
\text { value }\end{array}$ & Crude 0Rs (95\% CI) & $\begin{array}{c}\text { Low } \\
\text { distress } \\
n=197 \\
(\%)\end{array}$ & $\begin{array}{c}\text { High } \\
\text { distress } \\
n=197 \\
(\%) \\
\end{array}$ & $\begin{array}{c}p- \\
\text { value }\end{array}$ & Crude ORs $(95 \% \mathrm{CI})$ \\
\hline \multicolumn{9}{|c|}{ Decision making } \\
\hline High & $1,083(79.5)$ & $813(73.2)$ & & & $156(79.2)$ & $143(72.6)$ & & \\
\hline Low & $279(20.5)$ & $298(26.8)$ & $>0.001$ & $1.42(1.18-1.72)$ & $41(20.8)$ & $54(27.4)$ & 0.13 & $1.44(0.88-2.35)$ \\
\hline \multicolumn{9}{|l|}{ Self efficacy } \\
\hline High & $1,024(75.2)$ & $801(72.1)$ & & & $128(65.0)$ & $123(62.4)$ & & \\
\hline Low & $338(24.8)$ & $310(27.1)$ & 0.08 & $1.17(0.98-1.41)$ & $69(35.0)$ & $74(37.6)$ & 0.60 & $1.12(0.73-1.72)$ \\
\hline \multicolumn{9}{|l|}{ Empathy } \\
\hline High & $764(56.1)$ & $562(50.6)$ & & & $136(69.0)$ & $105(53.3)$ & & \\
\hline Low & $598(43.9)$ & $549(49.4)$ & 0.006 & $1.25(1.06-1.47)$ & $61(31.0)$ & $92(46.7)$ & 0.001 & $1.95(1.27-3.01)$ \\
\hline \multicolumn{9}{|c|}{ Emotional awareness } \\
\hline High & $920(67.5)$ & $656(59.0)$ & & & $153(77.7)$ & $121(61.4)$ & & \\
\hline Low & $442(32.5)$ & $455(41.0)$ & $>0.001$ & $1.44(1.22-1.71)$ & $44(22.3)$ & $76(38.6)$ & $>0.001$ & $2.18(1.37-3.48)$ \\
\hline \multicolumn{9}{|c|}{ Coping with emotions } \\
\hline High & $783(57.5$ & $582(52.4)$ & & & $117(59.4)$ & $116(58.9)$ & & \\
\hline Low & $579(42.5)$ & $529(47.6)$ & 0.01 & $1.23(1.05-1.45)$ & $80(40.6)$ & $81(41.1)$ & 0.92 & $1.02(0.67-156)$ \\
\hline \multicolumn{9}{|c|}{ Coping with stress } \\
\hline High & $451(33.1)$ & $347(31.2)$ & & & $67(34.0)$ & $77(39.1)$ & & \\
\hline Low & $911(66.9)$ & $764(68.8)$ & 0.32 & $1.09(0.92-1.29)$ & $130(66.0)$ & $120(60.9)$ & 0.29 & $0.80(0.52-1.24)$ \\
\hline \multicolumn{9}{|c|}{ Accurate self assessment } \\
\hline High & $1,094(80.3)$ & $850(76.5)$ & & & $133(67.5)$ & $111(56.3)$ & & \\
\hline Low & $268(19.7)$ & $261(23.5)$ & 0.02 & $1.26(1.03-1.53)$ & $64(32.5)$ & $86(43.7)$ & 0.02 & $1.61(1.05-2.48)$ \\
\hline \multicolumn{9}{|c|}{ Self confidence } \\
\hline High & $1,099(80.7)$ & $836(75.2)$ & & & $153(77.7)$ & $120(60.9)$ & & \\
\hline Low & $263(19.3)$ & $275(24.8)$ & 0.001 & $1.38(1.13-1.67)$ & $44(22.3)$ & $77(39.1)$ & $>0.001$ & $2.23(1.40-3.55)$ \\
\hline
\end{tabular}

Residence, distress associated with life events; PSC domains of decision making/problem solving, coping with emotions and coping with stress did not show a significant association as shown in Table 4. However, the final step in the regression model showed that male study participants (Adjusted OR 0.71; 95\% CI: $0.57-0.88, \mathrm{p}=0.002)$ and those with a high score on emotional awareness (Adjusted OR 0.69; 95\% CI: 0.54
- $0.85 \mathrm{p}=0.001)$ were more likely to be from the Central region. Those that had low susceptibility to stress related illness (Adjusted OR 1.97; 95\% CI: 1.57 - 2.48, p = 0.000 ); had a high score on self-efficacy, (Adjusted OR 1.37; 95\% CI: $1.09-1.74, p=0.008)$; a high score on self-confidence (Adjusted OR 1.32; 95\% CI: 1.02 - 1.72, $\mathrm{p}=0.037)$ and a high score on accurate self-assessment (Adjusted OR 2.19; 95\% CI: $1.70-2.80, \mathrm{p}=0.000$ ) were more likely to be from the Northern region. 
Table 4: Logistic Regression Analysis Explaining Placement of Students by Region

\begin{tabular}{|l|c|c|c|}
\hline Characteristic & P-value & $\begin{array}{c}\text { Adjusted } \\
\text { Odds Ratio }\end{array}$ & $\begin{array}{c}\mathbf{9 5 \%} \text { Confidence } \\
\text { Interval }\end{array}$ \\
\hline Rural residence & NS & 1.44 & $(0.14-15.03)$ \\
\hline Being male by gender & $\mathbf{0 . 0 0 2}$ & $\mathbf{0 . 7 1}$ & $\mathbf{( 0 . 5 7 - 0 . 8 8 )}$ \\
\hline Low susceptibility to stress related illness & $\mathbf{0 . 0 0 0}$ & $\mathbf{1 . 9 7}$ & $\mathbf{( 1 . 5 7 - 2 . 4 8 )}$ \\
\hline High distress associated with negative daily hassles & NS & 1.66 & $(0.85-1.33)$ \\
\hline Low distress associated with positive daily hassles & NS & 1.17 & $(0.94-1.46)$ \\
\hline Scoring highly on decision making/problem solving & NS & 1.09 & $(0.84-1.43)$ \\
\hline Scoring highly on self efficacy & $\mathbf{0 . 0 0 8}$ & $\mathbf{1 . 3 7}$ & $\mathbf{( 1 . 0 9 - 1 . 7 4 )}$ \\
\hline Scoring highly on empathy & NS & 0.79 & $0.62-1.01$ \\
\hline Scoring highly on emotional awareness & $\mathbf{0 . 0 0 1}$ & $\mathbf{0 . 6 9}$ & $\mathbf{( 0 . 5 4 - \mathbf { 0 . 8 5 } )}$ \\
\hline Scoring highly on coping with emotions & NS & 0.91 & $(0.72-1.15)$ \\
\hline Scoring highly on coping with stress & NS & 0.81 & $(0.64-1.02)$ \\
\hline Scoring highly on self confidence & $\mathbf{0 . 0 3 7}$ & $\mathbf{1 . 3 2}$ & $\mathbf{( 1 . 0 2 - 1 . 7 2 )}$ \\
\hline Scoring highly on accurate self assessment & $\mathbf{0 . 0 0 0}$ & $\mathbf{2 . 1 9}$ & $\mathbf{( 1 . 7 0 - 2 . 8 0 )}$ \\
\hline
\end{tabular}

\section{Discussion}

This study set out to determine the prevalence of life events in secondary school students in Central and Northern Uganda. Secondly, it was to describe the relationship between life events and psychosocial competence. The students from Northern Uganda had a significantly higher likelihood of being susceptible to stress-related illness associated with major life events. This could be related to the prolonged exposure to war trauma ${ }^{4,35}$. It is known that life stress leads to decrease in perceived control and increase in helplessness, which can potentially make adolescents susceptible to negative coping, typified by substance use $\mathrm{e}^{20,25}$.

Unlike in the Central region where no differences were apparent, students from Northern Uganda with low scores on accurate self-assessment and self-confidence were significantly more likely to have a high susceptibility to stress-related illness. Stratified analysis by region also showed that young people from the Central region with low scores on empathy, emotional awareness and self-confidence scored highly on susceptibility to stress-related illnesses. Although it is probable that prolonged exposure to conflict in the north could have undermined PSC which is a known resource for successful coping and resilience, past research elsewhere has already demonstrated the preeminent role of human resilience and capacity to thrive after extremely aver- sive events ${ }^{36}$. In the Northern region, the proportion of students with a low susceptibility to stress related illness was significantly higher among those who scored highly on decision making/problem solving and coping with emotions illness. Already, a problem-focused coping style was found to decrease perceived stress and increase perceived efficacy and an emotion-oriented coping style was negatively associated with these outcomes ${ }^{48}$.

Generally, students from both regions had high levels of distress associated with negative life events. This is consistent with past observations suggesting that globally; children and young people exposed to major crises and sustained lifestyle alterations like youth unemployment, parental separation and divorce, academic stress, teenage and belonging to single parent families display elevated distress ${ }^{37}$. However, students from Northern Uganda had more experiences of negative war-related events (e.g., seeing dead bodies, being threatened) ${ }^{49}$. Past research shows that negative life events elevate negative affect and place the adolescent at increased risk of negative behavior like substance use ${ }^{25}$. Although boys and girls are vulnerable to developing depressive reactions to stress during adolescence ${ }^{2}$, exposure to war-trauma in Northern Uganda rendered students from there to be more reactive than those from Central Uganda. Students from both regions that had proportionately 
higher scores on empathy, emotional awareness, accurate self- assessment and self-confidence were likely to have low levels of distress associated with positive life events. Notwithstanding the exposure to different trauma, students that were psychosocially competent in these domains seemed to cope well with distressing life events. This resonates with a known hypothesis which posits that emotional competencies (including self-control, resilience, social skills, conscientiousness, reliability, integrity, and motivation) interact with organizational climate and job demands to influence performance ${ }^{38-40}$. The resulting emotional resilience associated with these PSC domains could be responsible for the better management excessive distress associated with life events. It was only in the Central region that 'decision making' and 'coping with emotions' were additional PSC domains to be associated with lower levels of distress associated with positive life events.

In logistic regression, significantly more male students tended to be from the Central region. Although more males tended to report more violence, there were regional differences in form and experience of violence. Violence in the Central region was known to be perversely related to crime and pressures of urban living while that in Northern Uganda was until recently associated with war and internal displacement ${ }^{4,35,41,42}$. Students with higher scores on emotional awareness tended to be from the central region, probably due to the academic and psychosocial stimulation common in urban area. On the other hand, students that had a low susceptibility to stress related illness, a high score on self-efficacy, a high score on self-confidence, and a high score on accurate self- assessment tended to more likely be from the northern region. The explanation for this could be in their resilience that is often associated with post-conflict and post-disaster serenity ${ }^{36,43,44}$. Alternatively, such a finding could be explained by the vicarious hardiness harnessed from years of exposure to harsher life-challenges when the war in the area was very active. This is consistent with a view that; in younger populations, resilience of children and adolescents to the effects of stressful life events is common ${ }^{45-47}$.

\section{Methodological Limitations}

There are inherent methodological weaknesses with the study design used. The research design was cross sectional; hence the conclusions reached are not definitive about causal direction. One common weakness with retrospective studies like this one is the threat imposed by distortions in recall. Respondents are required to recall life events that happened in their past. Unlike in observer-rated instruments, self-rating scales like the one we used does lends itself to helping the respondents reorganize personal facts from the past. Research instruments used in this study were developed in other cultures and are yet to be validated in Uganda's multicultural setting. However, a consistent adaptation approach was employed, taking into account cultural differences. The relatively big sample size was comparable to other related studies ${ }^{25}$.

Besides, the big sample size increased the power of the study. This rendered our findings not only to be comparatively credible but generalizeable as well. Data collected and subsequent interpretation of findings is reasonably valid and reliable for programming and policy purposes. Future research in the study subject would be more helpful if it could be interventional and adopt a longitudinal research design. The presented findings are promising but they also suggest the need for additional research on these issues. For instance, elucidation and clarification of the nature of coping with life stressors in income-constrained societies during adolescence and how to measure this coping remains a virgin research area. It is necessary to look for factors and processes that may be common to effective coping across a wide variety of stressful experiences.

\section{Conclusion}

The results of this research raise issues for considerations in primary prevention of psychosocial dysfunction in adolescents. First, the results show an association between negative life events and PSC domains and add to previous research on adolescent life events and dysfunctional outcomes. The implication is that it is important to focus on helping students to cope with negative life events. Finally, the present data emphasize the relationship of specific competencies to life events. The PSC domains of empathy, emotional awareness, accurate self-assessment and self-confidence were associated with a lower distress levels associated with positive life events, implying that these should be reinforced.

\section{Abbreviations}

AOR: Adjusted Odds Ratio; CI: Confidence Interval; ECI: The Emotional Competence Inventory; OR: Odds Ratio; PSC: Psychosocial competence; SD: Standard Deviation; SPSS: Statistical Package for the Social Scientists; SSA: Sub Saharan Africa 


\section{Acknowledgments}

The work was supported by Training Health Researchers into Vocational Excellence (THRiVE) in East Africa, Grant number 087540, funded by Wellcome Trust. We thank the research assistants and all study participants for their invaluable contributions to the study.

\section{Contribution of authors}

All the authors contributed equally to this manuscript

\section{Declaration of conflicting interests}

The authors declare no conflicts of interest with respect to the authorship and/or publication of this article.

\section{References}

1. Compas BE, Davis GE, Forsythe CJ. Characteristics of Life Events During Adolescence. Am J of Comm Psychol. 1985;13(6):677-91.

2. Ge X, Lorenz FO, Conger RD, Elder Jr GH, Simons RL. Trajectories of Stressful Life Events and Depressive Symptoms During Adolescence. Dev Psychol. 1994;30(4):467-83.

3. Hamburg BA. Early adolescence: A specific and stressful stage of the life cycle. In: Coelho GV, Hamburg BA, Adams JE, editors. Coping and adaptation: New York: Basic Books; 1974.

4. Amone-P'Olak K. Mental states of adolescents exposed to war in Uganda: finding appropriate methods of rehabilitation. Torture. 2006;16(2):93-107.

5. McMullen JD, O'Callaghan PS, Richards JA, Eakin JG, Rafferty H. Screening for traumatic exposure and psychological distress among war-affected adolescents in post-conflict northern Uganda. Soc Psychiatry Psychiatr Epidemiol. 2012;Sep;47(9):1489-98.

6. Abbo C, Okello ES, Muhwezi WW, Akello G, Ovuga EBL. Alcohol, Substance Use and Psychosocial Competence of Adolescents in Selected Secondary Schools in Uganda: A Cross Sectional Survey. Int Neuropsychiatr Dis J 2016;7(2):7-14.

7. Hendren R, Weisen RB, Orley J. Mental health programmes in schools. Geneva, World Health Organization; 1994.

8. Okello ES, Abbo C, Muhwezi WW, Akello G, Ovuga E. Mental health literacy among secondary school students in North and Central Uganda: a qualitative study World Cultural Psychiatry Research Review. 2014;9(3):70-80.

9. Paykel ES. Life events, social support and depression. Acta Psycbiat Scand. 1994;377:50-8.

10. Rafanelli C, Roncuzzi R, Milaneschi Y, Tom- ba E, Colistro MC, Pancaldi LG, et al. Stressful life events, depression and demoralization as risk factors for acute coronary heart disease. Psychother Psychosom. 2005;74(3):179-84.

11. Brown GW, Harris TO. The Social Origins of Depression: A study of Psychiatric Disorders in Women. London: Tavistock Publications; 1978.

12. Dohrenwend BS. Events as stressors: a methodological inquiry. Journal of Health and Social Behavior. 1973;14(2):167-75.

13. Holmes TH, Rahe RH. The Social Readjustment Rating Scale. Journal of Psychosomatic Research. 1967;11(2):213-8.

14. Kendler KS, Karkowski-Shuman L. Stressful life events and genetic liability to major depression: genetic control of exposure to the environment? Psychol Med. 1997;27(3):539-47.

15. Paykel ES. The Interview for Recent Life Events. Psychol Med. 1997;27(2):301- 10.

16. Burghcs L. What happens to the children of one parent families? BMJ. 1994;308:1114-5.

17. Donovan A, Oddy M, Pardoe R, Ades A. Employment status and psychological well-being: a longitudinal study of 16 - year-old school leavers. J Child Psychol Psychiatry. 1986;27:65-76.

18. Goodyer IM. Family relationships, life events and childhood psychopathology. J Child Psychol Psychiatry. 1990;31:161-92.

19. Kovac M, Krol RS, Voti L. Early psychopathology and the risk for teenage pregnancy among clinically referred girls. J Am Acad Child Psy. 1994;33:106-14.

20. Tram JM, Cole DA. Self-Perceived Competence and the Relation Between Life Events and Depressive Symptoms in Adolescence: Mediator or Moderator? J Abnorm Psychol. 2000;109(4):753-60.

21. Brown GW. Life Events and Measurement. In: Brown GW, Harris TO, editors. Life events and Illness. New York: The Guilford Press; 1989.

22. Kessler RC. The effects of stressful life events on depression. Annual Review of Psychology. 1997;48:191214.

23. Muhwezi WW, Ågren $\mathrm{H}$, Neema S, Maganda AK, Musisi S. Life Events Associated With Major Depression in Ugandan Primary Healthcare (PHC) Patients: Issues of Cultural Specificity. Int J Soc Psychiatr. 2008;54(2):144-63.

24. Sarason IG, Johnson JH, Siegel JM. Assessing the impact of life changes: development of the Life Experiences Survey. Journal of Consulting and Clinical Psychology. 1978;46(5):932-46. 
25. Wills TA, Vaccaro D, McNamara G. The Role of Life Events, Family Support, and Competence in Adolescent Substance Use: A Test of Vulnerability and Protective Factors. Am J Comm Psychol. 1992;20(3):34973.

26. Saigh PA, Mroueh M, Bremner JD. Scholastic impairments among traumatized adolescents. Behav Res Ther. 1997;35(5):429-36.

27. Tyler FB. Psychosocial Competence in Developing Countries. Psychol Dev Soc J. 1991; 3(2):171-92.

28. Abbo C, Okello ES, Muhwezi WW, Akello G, Ovuga EBL. Concepts, prevalence and factors associated with psychosocial competence of young people in selected secondary schools in Northern and Central Uganda. BMC Psychiatry. Submitted.

29. Leslie K. Survey Sampling. New York: John Wiley and Sons, Inc1965.

30. Ministry of Education and Sports. EMIS statistical abstract. In. Kampala: Ministry of Education 2009 Available from: http://www.education.go.ug/emis- statistics/statistics-abstarct.html.

31. The education (pre-primary, primary and post-primary) Act, (2008).

32. Boyatzis RE, Goleman D, Rhee K. Clustering competence in emotional intelligence: Insights from the Emotional Competence Inventory (ECI). In: Bar- On R, Parker JD, editors. Handbook of Emotional Intelligence: San Francisco: Jossey-Bass; 1999.

33. Shahar G, Henrich CC, Reiner IC, Little TD. Development and Initial Validation of the Brief Adolescent Life Event Scale (BALES). Anxiety Stress Copin. 2003;16(1):119-28.

34. World Medical Association. Declaration of Helsinki: ethical principles for medical research involving human subjects. J Postgrad Med. 2002;48:206-8.

35. Derluyn I, Broekaert E, Schuyten G, Temmerman ED. Post-traumatic stress in former Ugandan child soldiers. Lancet. 2004;363(13):861-3.

36. Bonanno G. Loss, trauma and human resilience: have we underestimated the human capacity to thrive after extremely aversive events? Am Psychol. 2004;59:208.

37. Prosser J, McArdle P. The changing mental health of children and adolescents: evidence for a deterioration? Psychol Med. 1996;26(4):715-25.
38. Ohannessian CM, Lerner RM, Lerner JV, Eye A. Perceived parental acceptance and early adolescent self-competence. Am J Orthopsychiatry. 1998;68:621-9.

39. American Psychological Association. Developing Adolescents: A Reference for Professionals. 750 First Street, NE. Washington, DC 20002-4242. Retrieved June 20, 2013 from http://www.apa.org/pi/ families/resources/develop.pdf2002.

40. Abraham R. Emotional Competence as Antecedent to Performance: A Contingency Framework. Genet Soc Gen Psych. 2004;130(2):117-43.

41. Wyrzykowski P, Kasozi OB. Violence, Exile and Transitional Justice: Perspectives of Urban IDPs in Kampala: A briefing Note. Vol 3. 2009.

42. Kaplan Suzanne. A research review; Children in Africa with experiences of massive trauma. Edita Communication AB, SIDA Department for Research Cooperation; www.sida.se/publications; 2005.

43. Alvarez-Castillo F, Okuonzi S, Chabikuli N, Lomorro O, Atuyambe L, Silva KT. Why some survive: coping, resilience and social capital in armed conflict. African Safety Promotion; A Journal of Injury and Violence Prevention. 2006;4:78-87.

44. Bhugra D, van Ommeren M. Mental health, psychosocial support and the tsunami. Int Rev Psychiatry. 2006;18:213-6.

45. Cowen EL, Work WC, Wyman PA. The Rochester Child Resilience Project (RCRP): Facts found, lessons learned, future directions divined. In: Luthar SS, Burack JA, editors. Developmental psychopathology: Perspectives on adjustment, risk, and disorder. New York: Cambridge University Press; 1997. p. 527-47.

46. Egeland B, E. C, Sroufe LA. Resilience as process. Dev Psychopathol. 1993;5:517-28.

47. Joseph JM. The resilient child: Preparing today's youth for tomorrow's world. New York: Insight Books; 1994.

48. Lavoie JAA.Eye of the Beholder: Perceived Stress, Coping Style, and Coping Effectiveness Among Discharged Psychiatric Patients. Arch Psychiatr Nurs. 2013; 27(4) 185-190.

49. Natalie D. Eggum ND, Sallquist I , and Eisenberg N. "Then It Will Be Good": Negative Life Events and Resilience in Ugandan Youth. Journal of Adolescent Research 26(6) 766-796 